\title{
Analisis Produksi Ikan Tahun 2015 - 2018 (Studi Kasus: Pelabuhan Perikanan Nusantara (PPN) Pemangkat)
}

\author{
Fish Production Analysis on 2015 - 2018 (Case Study: Pelabuhan \\ Perikanan Nusantara (PPN) Pemangkat)
}

\author{
Berza Husnul Khatimah ${ }^{1}$, Harmoko $^{1 *}$, Uray Dian Novita ${ }^{1}$
}

${ }^{1}$ Politeknik Negeri Sambas

\begin{abstract}
Info Artikel:
Diterima : Feb 2021

Disetujui : Mar 2021

Dipublikasi : Mar 2021
\end{abstract}

\section{Kata Kunci:}

Alat Tangkap, Gross tone,

Produksi Ikan, Trip,

Pelabuhan Perikanan

Nusantara Pemangkat.

\section{Keywords:}

Catch tools, Gross Tone, fish Production, Trip, PPN Pemangkat.

*Korespondensi: harmoko.ok@gmail.com

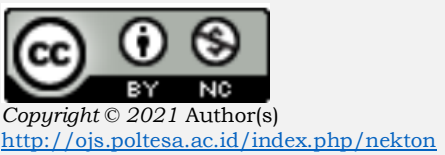

\begin{abstract}
Abstrak. Produksi ikan tahun 2015 - 2018 di Pelabuhan Perikanan Nusantara (PPN) Pemangkat memberikan sumbangan terhadap produksi nasional. Produksi ikan di Pelabuhan Perikanan Nusantara (PPN) Pemangkat tentunya memiliki dinamika ikan dalam setiap tahunnya, sehingga perlu diketahui penyebabnya. Tujuan dari penelitian ini adalah untuk mengetahui kondisi produksi ikan hasil tangkapan di Pelabuhan Perikanan Nusantara (PPN) Pemangkat tahun 2015 - 2018. Metode yang digunakan dalam penelitian ini adalah metode deskriptif dengan jenis penelitian kuantitatif dan sampel yang digunakan berupa data produksi ikan tahun 2015 - 2018. Produksi hasil tangkapan ikan tertinggi terjadi pada tahun 2018 yaitu sebesar $11.041 .325 \mathrm{~kg}$ dan hasil produksi ikan terendah terjadi pada tahun 2015 yaitu sebesar $8.574 .379 \mathrm{~kg}$. Hasil analisis regresi pengaruh variabel bebas (alat tangkap, gross tone, trip) terhadap variabel terikat (produksi ikan) diperoleh variabel yang berpengaruh adalah trip dan gross tone.
\end{abstract}

\begin{abstract}
The fish production on 2015 - 2018 at Pelabuhan Perikanan Nusantara (PPN) Pemangkat made a donation to national production. Fish production at Pelabuhan Perikanan Nusantara (PPN) Pemangkat certainly has dynamics of the fish every year, the causes need to be known. The purpose of this study is to know the conditions of caught fish production at Pelabuhan Perikanan Nusantara (PPN) Pemangkat in $2015-2018$. The method used in this study is a descriptive method with the kind of research that quantitative and the sample used as data for fish production on 2015 - 2018. The highest catch of fish is in 2018 at $11.041 .325 \mathrm{~kg}$ and the lowest production of fish occurred in 2015 at $8.574 .379 \mathrm{~kg}$. Regression analysis of free variable influence (catch tool, gross tone, trip) on bonded variables (fish production) obtained variable influence are trip and gross tone.
\end{abstract}

\section{PENDAHULUAN}

Produksi ikan mencakup semua hasil penangkapan ikan/binatang air lainnya yang ditangkap dari sumber perikanan alami baik yang diusahakan oleh perusahaan perikanan maupun rumah tangga perikanan. Produksi tidak hanya jumlah penangkapan yang dijual, tetapi termasuk juga hasil penangkapan yang dimakan nelayan/rumah tangga perikanan atau yang diberikan kepada nelayan sebagai upah kerja.

Produksi perikanan mempunyai peran yang sangat penting dalam pengembangan ekonomi maupun sosial. Permintaan terhadap produkproduk laut semakin hari semakin meningkat mengakibatkan terjadinya perdagangan yang semakin besar guna memenuhi kebutuhan pasar. Untuk memenuhi kebutuhan pasar maka perlu ada peningkatan jumlah operasi

Khatimah, B. H., Harmoko, \& Novita, U. D. (2021). Analisis Produksi Ikan Tahun 2015 - 2018 (Studi Kasus: Pelabuhan Perikanan Nusantara (PPN) Pemangkat). NEKTON: Jurnal Perikanan Dan Ilmu Kelautan, 1(1), 44-51. https://doi.org/10.47767/nekton.v1i1.269 
penangkapan. Keberhasilan operasi penangkapan ikan dipengaruhi oleh banyak faktor diantaranya adalah alat tangkapnya sendiri, kapal, alat bantu serta sumber daya manusia yang mengoperasikannya. Sumberdaya manusia yang handal juga sangat diperlukan dalam keberhasilan penangkapan ikan. Ketepatan analisa dalam penentuan fishing ground dan keterampilan dalam manajemen kegiatan di kapal (Sangadji, 2013).

Kegiatan perikanan tangkap di Pemangkat berkembang dengan baik, hal ini didukung dengan berdirinya Pelabuhan Perikanan Nusantara yang ada di Kecamatan Pemangkat. Produksi hasil perikanan tangkap yang didaratkan di Pelabuhan Perikanan Nusantara Pemangkat merupakan hasil tangkapan kapal perikanan dengan alat tangkap yang berbeda-beda. Selain alat tangkap, ukuran kapal atau gross tone (GT) menjadi ukuran dalam membantu peningkatan produksi ikan. Ukuran kapal di PPN Pemangkat terdiri dari 5 GT, 10 GT dan >100 GT.

Besar kecilnya kapal akan menentukan lamanya trip. Trip merupakan lamanya nelayan melakukan perjalanan dalam menangkap ikan. Dalam satu kali trip lamanya waktu dalam hitungan jam, hari bahkan bulan. Semakin sering nelayan melakukan trip, maka semakin banyak ikan yang ditangkap. Alat tangkap, GT dan trip di PPN Pemangkat memiliki rekam data yang memberikan peningkatan produksi ikan. Namun hal itu perlu penelitian yang menerangkan pengaruh alat tangkap, GT, dan trip.

Berdasarkan data dari PPN Pemangkat produksi ikan tahun 2015 2018 mengalami peningkatan. Oleh karena itu perlu dilakukan analisis tentang peningkatan produksi ikan. Pelabuhan Perikanan Nusantara Pemangkat memiliki kapal perikanan dengan alat tangkap yang berbeda-beda yaitu Purse Seine, Gillnet, bouke ami, kapal lampu, kapal angkut, pancing dan lampara dasar. Alat tangkap tersebut tentunya menjadi salah satu faktor dalam peningkatan produksi ikan.

Berdasarkan uraian di atas, maka penulis tertarik untuk melakukan penelitian tentang analisis produksi ikan tahun 2015 - 2018 di Pelabuhan Perikanan Nusantara Pemangkat. Penelitian ini penting dilakukan untuk mengetahui jumlah produksi rata-rata ikan pada tahun 2015 - 2018 di PPN Pemangkat, serta faktor -faktor apa saja yang mempengaruhi produksi ikan di PPN Pemangkat.

\section{METODE PENELITIAN}

Penelitian ini dilakukan pada bulan Juli tahun 2020 berlokasi di Pelabuhan Perikanan Nusantara (PPN) Pemangkat, di Desa Panjajab, Kecamatan Pemangkat, Kabupaten Sambas. Jenis penelitian yang digunakan ialah penelitian kuantitatif dengan metode deskriptif. Kemudian, penentuan sampel PPN Pemangkat menjadi objek penelitian dengan sengaja (purposive) atau dengan kriteria tertentu yakni terdapat peningkatan produksi dan 
menjadi salah satu penunjang produksi ikan Nasional. Sehingga data produksi ikan di PPN Pemangkat menjadi data primer penelitian. Selain itu, variabel bebas (independent variable) pada penelitian ini adalah jumlah alat tangkap, jumlah ukuran kapal dan lama trip melaut di PPN Pemangkat tahun 2015 - 2018 sedangkan variabel tidak bebas (dependent variable) ialah data produksi ikan tahun 2015 - 2018.

\section{Teknik Analisis Data}

Analisis data yang digunakan untuk menjawab tujuan kedua pada penelitian ini dengan menggunakan Analisis Regresi Linier Berganda menggunakan SPSS versi 25. Regresi linier berganda merupakan salah satu pengujian untuk mengetahui pengaruh antara variabel bebas (independen) terhadap variabel tetapnya (dependen). Persamaan fungsi regresi linier berganda dinyatakan dengan rumus:

$\mathrm{Y}=\mathrm{a}+\mathrm{b}_{1} \mathrm{X}_{1}+\mathrm{b}_{2} \mathrm{X}_{2}+\mathrm{b}_{3} \mathrm{X}_{3}$

Ket :

$\mathrm{Y}$

A

$\mathrm{b}_{1}, \mathrm{~b}_{2}, \mathrm{~b}_{3}$

$\mathrm{X}_{1}$

$\mathrm{X}_{2}$

$\mathrm{X}_{3}$
: produksi ikan di PPN Pemangkat

: konstanta

: koefisien regresi

: alat tangkap

: jumlah ukuran kapal

: lama trip melaut.

\section{HASIL DAN PEMBAHASAN}

\section{Analisis regresi linear berganda tahun 2015 - 2018}

Analisis pengaruh alat tangkap, gross tone, dan trip terhadap produksi hasil tangkapan yang didaratkan di Pelabuhan Perikanan Nusantara Pemangkat tahun 2015 - tahun 2018 dengan metode analisis regresi linear berganda menggunakan SPSS 25 dapat dilihat pada Tabel 1.

Tabel 1. Koefisien determinasi $\left(\mathrm{R}^{2}\right)$ tahun $2015-2018$

\begin{tabular}{|c|c|c|c|c|}
\hline \multicolumn{5}{|c|}{ Model Summary } \\
\hline & & & & Std. Error of the \\
\hline Model & $\mathrm{R}$ & R Square & Adjusted R Square & Estimate \\
\hline 1 & $.745^{a}$ & .556 & .525 & 198293.337 \\
\hline
\end{tabular}

a. Predictors: (Constant), Trip, Alat Tangkap, Gross Tone

Dari perhitungan Tabel 1 diperoleh korelasi $\mathrm{R}$ sebesar 0,745. Hal ini menunjukkan bahwa terjadi hubungan antara jumlah alat tangkap, gross 
tone, dan trip terhadap produksi hasil ikan. Nilai $R$ square yaitu 0,556 yang berarti pengaruh jumlah alat tangkap, gross tone, dan trip terhadap produksi hasil ikan sebesar 55,6\% sedangkan sisanya 44,4\% dipengaruhi oleh faktorfaktor lain diluar model. Koefisien model regresi dapat dilihat dari tabel hasil uji berdasarkan output SPSS versi 25 terhadap tiga variabel bebas yaitu alat tangkap, GT kapal, trip melaut terhadap hasil produksi ikan tahun 2015 tahun 2018 di Pelabuhan Perikanan Nusantara Pemangkat dapat dilihat pada Tabel 2 berikut :

\begin{tabular}{|c|c|c|c|c|c|c|}
\hline & & Coefficients $^{a}$ & \multirow{2}{*}{\multicolumn{2}{|c|}{$\begin{array}{c}\text { Standardized } \\
\text { Coefficients } \\
\text { Beta }\end{array}$}} & \multirow[b]{2}{*}{$\mathrm{t}$} & \multirow[b]{2}{*}{ Sig. } \\
\hline Model & & $\begin{array}{c}\text { Unstandardize } \\
\text { d B }\end{array}$ & & & & \\
\hline 1 & (Constant) & 1097655.150 & 150557.579 & & 7.291 & .000 \\
\hline & Alat Tangkap & 30325.050 & 32330.136 & .097 & .938 & .353 \\
\hline & Gross Tone & -24811.628 & 3462.961 & -.760 & -7.165 & .000 \\
\hline & Trip & -366.573 & 342.341 & -.116 & -1.071 & .290 \\
\hline
\end{tabular}

a. Dependent Variable: Produksi

Berdasarkan hasil regresi diatas dapat disimpulkan bahwa pada tahun 2015 - 2018 variabel gross tone berpengaruh terhadap produksi ikan, sedangkan alat tangkap dan trip tidak berpengaruh.

\section{Produksi hasil tangkapan ikan}

Pelabuhan perikanan merupakan sarana dan prasarana, serta aktivitas - aktivitas yang terdapat didalamnya dapat memicu perkembangan ekonomi masyarakat khususnya nelayan. Keberhasilan Pelabuhan Perikanan terlihat melalui tercapainya target tangkapan ikan serta jumlah dan nilai produksi hasil tangkapan yang didaratkan. Dibalik itu, perkembangan jumlah dan produksi hasil tangkapan disuatu Pelabuhan Perikanan atau pangkalan pendaratan ikan diduga dengan adanya aktivitas dan fasilitas didalamnya. Jumlah dan nilai produksi hasil tangkapan di Pelabuhan Perikanan Nusantara Pemangkat selama 4 tahun $(2015$ - 2018) terlihat perbedaan yang signifikan. Aktivitas pendaratan hasil tangkapan tentunya sangat berdampak pada jumlah dan nilai produksi disuatu Pelabuhan Perikanan atau pangkalan pendaratan ikan.

Produksi ikan yang didaratkan di Pelabuhan Perikanan Nusantara Pemangkat berasal dari hasil tangkapan kapal perikanan domisili dan kapal andon atau kapal pendatang diantaranya dari kepulauan riau dan pulau jawa. Hasil tangkapan yang didaratkan di Pelabuhan Perikanan Nusantara Pemangkat dicatat oleh petugas data produksi harian pada saat melakukan pembongkaran dan penimbangan ikan. Data yang dicatat meliputi jenis kapal, alat tangkap, jenis ikan dan berat hasil tangkapan ikan yang didaratkan di Pelabuhan Perikanan Nusantara Pemangkat.Penimbangan ikan 
di lakukan per jenis ikan, gunanya untuk mempermudah mengetahui jumlah hasil tangkapan per jenis ikan yang didapat.

Produksi ikan di Pelabuhan Perikanan Nusantara Pemangkat memiliki target atau kuota produksi disetiap tahunnya dan setiap awal tahun mengadakan target tahunan, pada tahun 2015 - 2018 jumlah produksi ikan setiap tahunnya mengalami peningkatan. Pada tahun 2015 memiliki target produksi yaitu $10.346,00 \mathrm{~kg}$ dengan pencapaian $8.574,38 \mathrm{~kg}$ sedangkan pada tahun 2016 target produksi yaitu $6.586 .320,00 \mathrm{~kg}$ dengan pencapaian $9.562,28 \mathrm{~kg}$. Pada tahun 2017 jumlah produksi dengan target $10.000,00 \mathrm{~kg}$ dengan pencapaian produksi yaitu $9.775,83 \mathrm{~kg}$ dan pada tahun 2018 target produksi yaitu $10.950,00 \mathrm{~kg}$ dengan pencapaian produksi yaitu $11.041,3 \mathrm{~kg}$.

Jumlah produksi yang di targetkan dan terealisasikan pada tahun 2015 - 2018 disetiap tahunnya berbeda ada yang terealisasikan dan ada yang belum tercapai, masalah utama target tangkapan ikan tidak tercapai adalah cuaca (gelombang, angina, arus) mempengaruhi hasil tangkapan, sedangkan untuk kapal asing tidak berpengaruh terhadap hasil tangkapan ikan semenjak Menteri Perikanan dan Kelautan Republik Indonesia ibu Susi Pudjiastuti menghentikan keberadaan kapal asing dalam operasi penangkapan ikan.

Upaya pihak Pelabuhan Perikanan Nusantara Pemangkat agar target tercapai yaitu dengan berusaha meningkatkan jumlah pendaratan ikan, mulai dari mencatat atau pendataan sesuai hasil produksi saat kapal bongkar sehingga hasil laporan yang di hasilkan tetap asli sesuai kondisi dan aktivitas yang ada di Pelabuhan Perikanan Nusantara Pemangkat, sehingga kebijakan kedepannya bisa lebih baik. Dalam upaya untuk meningkatkan data produksi ikan program KKP juga mendukung dengan memberikan kebijakan seperti memberikan izin untuk penambahan kapal perikanan di wilayah Pelabuhan Perikanan Nusantara Pemangkat, memperpanjang SIPI (Surat Izin Penangkapan Ikan), contohnya seperti kapal andon atau kapal luar yang mendaratkan dan menjual hasil tangkapannya di Pelabuhan Perikanan Nusantara Pemangkat harus memiliki izin di Provinsi Kalimantan Barat dan merupakan suatu kebijakan Pelabuhan Perikanan Nusantara Pemangkat dalam menerima kapal luar upaya untuk meningkatkan produksi.

Terciptanya suatu pelayanan yang baik di suatu Pelabuhan Perikanan merupakan suatu hal yang mutlak dan harus diusahakan, karena pelayanan merupakan salah satu kegiatan yang menentukan keberhasilan pengembangan dan pembangunan Pelabuhan Perikanan. Pelayanan jasa pelabuhan yang ada di Pelabuhan Perikanan Nusantara Pemangkat seperti penerbitan surat persetujuan berlayar (SPB), setiap kapal yang akan melaut akan mengajukan permohonan penerbitan surat bersetujuan berlayar (SPB) kepada petugas Syahbandar di Pelabuhan Perikanan dengan proses pengeluaran surat seperti melampirkan berkas - berkas dan jika persyaratan yang diajukan belum terpenuhi maka petugas Syahbandar akan menerbitkan 
surat pemberitahuan kekurangan persyaratan administratif. Petugas Syahbandar akan melakukan pemeriksaan teknis dan nautis kapal perikanan, apabila belum terpenuhi maka akan diterbitkan surat pemberitahuan kekurangan persyaratan teknis dan nautis kapal, setelah lengkap petugas Syahbandar akan melakukan verifikasi dan memproses SPB dan setelah terbit maka akan dilakukan pengecapan, penyerahan dan pengarsipan SPB. Jenis ikan dominan di Pelabuhan Perikanan Nusantara Pemangkat seperti tongkol abuabu, tongkol banyar, tenggiri, layang, bawal hitam, layaran, manyung dan cumi-cumi.

\section{Faktor - faktor yang mempengaruhi produksi ikan tahun 2015 - 2018}

Ketersediaan input produksi merupakan faktor penting agar kegiatan usaha penangkapan ikan dapat berjalan dengan lancar. Input produksi pada Pelabuhan Perikanan Nusantara Pemangkat meliputi, ketersediaan teknologi penangkapan (kapal, alat, mesin, dan perlengkapan lainnya), ketersediaan sumberdaya manusia (SDM), ketersediaan modal, ketersediaan perbekalan operasi (BBM, air bersih, es) dan ketersediaan informasi. Lebih lanjut dijelaskan berbagai faktor akan berpengaruh terhadap keberhasilan produksi hasil tangkapan diantaranya, ukuran kapal (gross tone), jumlah trip, dan jenis alat tangkap. Penyiapan faktor produksi yang baik merupakan penentu utama keberhasilan kegiatan produksi (Sutisna, 2007). Pelaku ekonomi termasuk nelayan umumnya akan melakukan kegiatan operasi pada kondisi cuaca baik dan diduga akan membawa hasil yang banyak, sehingga kesiapan faktor produksi menjadi penentu akhir keberhasilan kegiatan produksi.

Hasil analisis regresi berganda menunjukkan bahwa ukuran kapal atau gross tone $\left(\mathrm{X}_{2}\right)$ dan jumlah trip $\left(\mathrm{X}_{3}\right)$ sangat berpengaruh terhadap produksi ikan di Pelabuhan Perikanan Nusantara Pemangkat pada tahun 2015 - 2018. Signifikansinya pengaruh ukuran kapal atau gross tone dan jumlah trip terhadap produksi ikan dikarenakan jika ukuran kapal atau gross tone besar maka ukuran palkah atau tempat penampungan ikan pada kapal berjumlah banyak sekitar 4 sampai 8 palkah untuk ukuran kapal > 50 GT, sedangkan jumlah trip berpengaruh karena daerah penangkapan ikan nelayan tidak menentu dan jika pada suatu daerah penangkapan nelayan tidak mendapatkan ikan maka nelayan akan berpindah mencari daerah penangkapan lain yang jauh dan jumlah hari melaut bertambah lama sehingga dalam sebulan nelayan turun melaut sekitar $1-2$ kali trip.

Dari hasil penelitian lapangan menyatakan sekali melakukan trip operasi penangkapan ikan rata-rata nelayan pelabuhan perikanan menggunakan ukuran kapal sekitar 5 -95 GT dengan kebutuhan perbekalan rata - rata solar $1.000-8.000$ liter, air bersih $2.000-12.000$ liter, gas $12 \mathrm{~kg}$ (3 - 9 tabung), es 5 - 20 ton, oli 10.000 - 50.000 liter, ransum Rp.1.500.000 Rp. 5.000.000 sedangkan untuk jumlah trip setiap jenis alat tangkap berbeda pada jenis alat tangkap gillnet dalam sebulan sekitar 2 kali trip, alat tangkap 
purse sein 1 kali trip dan alat tangkap bouke ami 1 kali trip. Rasio ukuran kapal dan lama trip wajar menjadikan kedua faktor produksi ini tidak dapat dilepaskan dari keberhasilan operasi perikanan di Pelabuhan Perikanan Nusantara Pemangkat. Berdasarkan hasil penelitian jumlah trip berpengaruh karena sekali melakukan operasi penangkapan jumlah trip tidak bisa di pastikan karena tergantung dari faktor lain seperti cuaca, kerusakan mesin, dan kerusakan benang nilon, hal ini menghambat kerja nelayan dalam memperoleh ikan dalam sekali trip.

Faktor produksi yang paling berpengaruh terhadap produktivitas adalah jumlah ukuran kapal atau gross tone, Jumlah gross tone berpengaruh besar dikarenakan tempat penampungan hasil tangkapan ikan atau palkah juga memiliki ruang penyimpanan yang luas sehingga jumlah hasil tangkapan ikan yang didapat akan berjumlah tinggi dalam satu kali trip. Sedangkan jumlah trip juga berpengaruh terhadap hasil produksi semakin sering frekuensi operasi penangkapan ,maka peluang untuk mendapatkan hasil tangkapan semakin besar pula.

Suatu faktor produksi dapat sangat serius mempengaruhi produksi ikan suatu usaha perikanan tangkap, sementara untuk perikanan lainnya mungkin tidak berpengaruh. Setiap kegiatan produksi mempunyai kebutuhan tersendiri yang unik terhadap setiap faktor produksi (Soekartawi, 2002). Peningkatan kebutuhan akan suatu faktor produksi umumnya tidak bersifat linear terhadap peningkatan hasil dari produksi yang dilakukan. Pengembangan produksi perikanan terlaksana dengan mengetahui strategi strategi apa saja yang harus dilakukan dengan memperhatikan faktor - faktor produksi, strategi - strategi yang dihasilkan dapat dibuat prioritas, mana yang lebih utama guna mengembangkan produksi perikanan di Pelabuhan Perikanan Nusantara Pemangkat.

\section{KESIMPULAN}

Hasil produksi ikan tahun 2015 - 2018 secara berurutan produksi ikan hasil tangkapan yang didaratkan di Pelabuhan Perikanan Nusantara Pemangkat sebesar $8.574 .379 \mathrm{~kg}, 9.562 .280 \mathrm{~kg}, 9.775 .834 \mathrm{~kg}, 11.041 .325 \mathrm{~kg}$ dengan rata - rata produksi per bulan secara berurutan $714.531 \mathrm{~kg}, 796.856$ $\mathrm{kg}, 814.652 \mathrm{~kg}, 920.110 \mathrm{~kg}$ dan produksi rata - rata per hari secara berurutan yaitu $23.817 \mathrm{~kg}, 26.561 \mathrm{~kg}, 27.155 \mathrm{~kg}, 30.670 \mathrm{~kg}$. Faktor - faktor yang mempengaruhi produksi ikan tahun 2015 - 2018 di PPN Pemangkat yaitu hasil perhitungan bahwa terdapat hubungan kuat antara alat tangkap, gross tone, dan trip terhadap volume produksi hasil tangkapan. Nilai $\mathrm{R}^{2}$ ( $\mathrm{R}$ square) $=0,556$ dengan demikian berarti bahwa pengaruh alat tangkap, gross tone, trip terhadap produksi hasil tangkapan adalah 55,6\%. Sedangkan sisanya $44,4 \%$ dipengaruhi oleh faktor-faktor lain diluar variabel. 


\section{DAFTAR PUSTAKA}

Sangadji, S., Mustaruddin., \& Hari, W. S. (2013). Pengaruh Faktor Produksi Terhadap Pengembangan Perikanan Tuna di Kota Ambon. Jurnal Teknologi Perikanan dan Kelautan, 4(1), 1-8.

Sutisna, D. H. (2007). Pola Pengembangan Perikanan Tangkap di Pantai Selatan Propinsi Jawa Barat. [Disertasi]. Sekolah Pascasarjana, IPB. Bogor.

Soekartawi. (2002). Teori Ekonomi Produksi dengan Pokok Bahasan Analisis Fungsi Produksi CobbDouglas. PT. Raja Grafindo Persada. Jakarta. 